\title{
Disgust Sensitivity is Primarily Associated with Purity-Based Moral Judgments
}

\author{
Fieke M. A. Wagemans
}

Mark J. Brandt

Marcel Zeelenberg

Tilburg University

Correspondence regarding this manuscript should be addressed to F.M.A.Wagemans@uvt.nl

Draft Date: 20 July 2017

Word count: 12273

C 2017, American Psychological Association. This paper is not the copy of record and may not exactly replicate the final, authoritative version of the article. Please do not copy or cite without authors permission. The final article will be available, upon publication, via its DOI:

10.1037/emo0000359 


\begin{abstract}
Individual differences in disgust sensitivity are associated with a range of judgments and attitudes related to the moral domain. Some perspectives suggest that the association between disgust sensitivity and moral judgments will be equally strong across all moral domains (i.e., purity, authority, loyalty, care, fairness, and liberty). Other perspectives predict that disgust sensitivity is primarily associated with judgments of specific moral domains (e.g., primarily purity). However, no study has systematically tested if disgust sensitivity is associated with moral judgments of the purity domain specifically, more generally to moral judgments of the binding moral domains, or to moral judgments of all of the moral domains equally. Across five studies (total $N=1104$ ), we find consistent evidence for the notion that disgust sensitivity relates more strongly to moral condemnation of purity-based transgressions (meta-analytic $r=.40$ ) than to moral condemnation of transgressions of any of the other domains (range meta-analytic $r$ 's: $.07-.27)$. Our findings are in line with predictions from Moral Foundations Theory, which predicts that personality characteristics like disgust sensitivity make people more sensitive to a certain set of moral issues.
\end{abstract}

Keywords: moral judgments, disgust, emotion, morality 


\section{Disgust Sensitivity is Primarily Associated with Purity-Based Moral Judgments}

Making moral judgments is in essence an emotional process (Haidt \& Kesebir, 2010). Automatic intuitive evaluations guide our reasoning about and judgments of moral situations. One replicable effect from this perspective is the association between individual differences in disgust sensitivity and attitudes towards (morally) deviant behaviors or individuals (e.g., Brenner \& Inbar, 2014; Chapman \& Anderson, 2014; Crawford, Inbar, \& Maloney, 2014; Hodson \& Costello, 2007; Inbar, Pizarro, \& Bloom, 2009; Inbar, Pizarro, Knobe, \& Bloom, 2009; Jarudi, 2009; Jones \& Fitness, 2008; Naverrete \& Fessler, 2006; Olatunji, 2008). People who score higher on trait disgust sensitivity tend to judge moral transgressions and other deviant behaviors as more morally wrong than people who score lower on this trait (e.g., Horberg, Oveis, Keltner, \& Cohen, 2009). It is not clear, however, if this association is general or if it is specific to a limited set of moral situations. While some perspectives predict that disgust sensitivity will be primarily related to moral judgments in specific moral domains (e.g., Graham et al., 2012), other perspectives suggest that disgust sensitivity will be associated with judgments across multiple moral domains (e.g., Cameron, Lindquist, \& Gray, 2015). However, to our knowledge, no study has tested these competing predictions by systematically comparing disgust sensitivity's effect on moral judgments across different moral domains. In five studies, we directly test if disgust sensitivity is related to moral judgments in the purity domain specifically, more generally to moral judgments in the binding moral domains, or to moral judgments in all of the moral domains.

\section{Disgust \& Disgust Sensitivity}

Disgust is the feeling of revulsion in response to an aversive stimulus, motivating withdrawal from that stimulus (Rozin, Haidt, \& McCauley, 2000). The word disgust is thought to 
essentially mean "something offensive to the taste" (Darwin, 1872, p. 257) and has been parsed into different disgust subtypes depending on the specific taste that is offended (Haidt, Rozin, McCauley, \& Imada, 1997; Tybur, Lieberman, \& Griskevicius, 2009). For example, one subtype is core disgust (sometimes called pathogen disgust) and it relates to the intake of potentially harmful foods. It likely evolved because it protects us from infectious diseases (Curtis \& Biran 2001; Rozin et al., 2000; Tybur, Lieberman, Kurzban, \& DeScioli, 2013). However, disgust is also thought to be co-opted by the social and moral domains.

People experience disgust (along with anger, contempt, and other negative emotions) following moral transgressions (Brandt \& Reyna, 2011; Cannon, Schnall, \& White, 2011; Haidt et al., 1997). These feelings cue people into the moral transgression that has occurred and motivates them to take action. For example, one study shows that people make disgusted facial expressions after receiving unfair offers in an Ultimatum Game (Chapman, Kim, Susskind, \& Anderson, 2009). Similarly, neurological research shows that core disgust and moral/social disgust elicit activation in overlapping brain areas (Borg, Lieberman, \& Kiehl, 2008). The basic idea is that disgust, whether it is the core or the moral subtype, can arise from moral transgressions and biases behavior away from risks due to physical or social parasites (Curtis \& Biran, 2001, also see Inbar \& Pizarro, 2014). A more controversial proposition is that induced feelings of disgust amplify unrelated moral judgments (i.e., make unrelated moral judgments harsher; e.g., Schnall, Haidt, Clore, \& Jordan, 2008; Wheatley \& Haidt, 2005); however, a recent meta-analysis (Landy \& Goodwin, 2015) and large scale replication attempts (Johnson et al., 2016) indicate that this effect is highly unstable and potentially very near zero.

Here, we sidestep that debate and focus on the association between individual differences in disgust sensitivity and moral judgments. Disgust sensitivity is an individual's proneness to 
experience disgust intensely or easily in response to aversive stimuli (also called trait disgust; Haidt, McCauley, \& Rozin, 1994). While state disgust can be very informative for specific situations, disgust sensitivity is stable over time and is predictive for a person's tendency to feel disgusted across a variety of disgust-eliciting stimuli and situations (Rozin, Haidt, McCauley, Dunlop, \& Ashmore, 1999). People who score higher on disgust sensitivity tend to score higher on neuroticism (Druschel \& Sherman, 1999; Haidt et al., 1994; Tybur \& De Vries, 2013) and a variety of fear-related measures, such as trait anxiety and animal phobia (De Jong \& Merckelbach, 1998; Matchett \& Davey, 1991; Muris, Merckelbach, Schmidt, \& Tierney, 1999), and they tend to have higher perceptions of vulnerability to diseases (Duncan, Schaller, \& Park, 2009).

Disgust sensitivity also has consistently been related to the moral domain. For example, it relates to people's moral values (i.e., the moral domains people think are most important; Graham, Nosek, Haidt, Iyer, Koleva, \& Ditto, 2011; Van Leeuwen, Dukes, Tybur, \& Park, 2017), the honesty-humility dimension of the HEXACO model of personality (Tybur \& De Vries, 2013), and harsher punishments in a mock trial (Jones \& Fitness, 2008). Although there has been a focus on investigating the association between disgust and moral cognition, some important questions are left unanswered. In this paper, we try to answer one such question. Namely, does disgust sensitivity relate to all kinds of moral judgments (i.e., the perceived wrongness of specific behaviors and situations), or is the association between disgust sensitivity and moral judgments domain specific? Although this question has elicited considerable discussion, no study, to our knowledge, has yet systematically tested the different perspectives in the literature against each other. 
We will do so by focusing on moral judgments of concrete behaviors and situations, which is important for two reasons. First, they allow for the impact of so-called moral intuitions. Moral intuitions are the instant feelings of approval or disapproval that come with witnessing moral transgressions and are known to play a substantial role in moral decision-making (Haidt, 2001). An individual's moral intuition about a given situation is directly fueled by that individual's emotional disposition, such as disgust sensitivity. Because making moral judgments of specific situations more strongly triggers such moral intuitions than measures focused on broad and sometimes abstract moral concerns, such as the Moral Foundations Questionnaire (Graham, Haidt, \& Nosek, 2009; Graham et al., 2011), they provide a more accurate reflection of how people make moral judgments in everyday life.

A second reason why it is important to focus on moral judgments of concrete behaviors

concerns the five criteria set by Graham and colleagues (2012, p. 37) that determine what counts as a moral domain. The first of these criteria is "a common concern in third-party normative judgments". More specifically, they argue that the existence of a domain can be doubted if there is a lack of response to third-party transgressions of that domain, even when people claim to endorse that broad moral concern. The idea behind this criterion is that people are motivated to enforce a certain norm, even when there are no direct implications for the self, thereby showing shared intentionality to uphold a certain norm. In order to show domain specific effects, it is therefore crucial to focus on moral judgments of third-party transgressions of these moral domains.

\section{Disgust Sensitivity \& Domains of Moral Judgment: Three Hypotheses}

Taxonomies of moral content suggest that the moral domain can be split into anywhere from three (Shweder, Much, Mahapatra, \& Park, 1997), to five (Graham et al., 2009) and six 
(Haidt, 2012; Janoff-Bulman \& Sheikh, 2012) moral domains. Some have argued against the existence of distinct moral domains, suggesting that all domains are a variation of one underlying construct (i.e., perceived harm; Schein \& Gray, in press). Although there are theoretical benefits and drawbacks to each of these taxonomies, in this paper we focus on the Moral Foundations taxonomy (for an overview, see Graham et al., 2012) because this perspective has most closely considered the role of disgust and is one of the most widely used taxonomies. The taxonomy from Moral Foundations Theory includes three domains that are often lumped together as binding foundations (i.e., moral domains that bind groups together and facilitate group cohesion; Haidt, 2008) and three domains that are often lumped together as individualizing foundations (i.e., moral domains that facilitate individual rights and responsibilities; Haidt, 2008). These six domains are listed and briefly described in Table 1. It is not clear how disgust sensitivity predicts moral judgments across these six domains. The moral psychology literature provides three, yet untested, hypotheses about the relation between disgust sensitivity and moral judgments in these domains.

Primarily Purity Hypothesis. The primarily purity hypothesis is the most specific hypothesis and predicts that disgust sensitivity will be associated with harsher judgments of moral transgressions of the purity domain more so than with judgments of moral transgressions in any of the other domains. This hypothesis is consistent with Moral Foundations Theory, which was developed to explain why some cultures or people are more sensitive to one set of moral issues, but not to other sets of moral issues (Graham et al., 2012). The degree to which one is morally sensitive to each of these domains depends on both cultural upbringing and personality. Disgust sensitivity is one such personality trait, and is thought to sensitize people to judgments in the purity domain because the concerns most relevant to the purity domain likely result from the 
same evolutionary problems as disgust. More specifically, Haidt (2012, p. 146) notes that "the original adaptive challenge that drove the evolution of the sanctity (i.e., purity) domain [...] was the need to avoid pathogens, parasites, and other threats that spread by physical touch or proximity" and even goes as far as saying that "if we had no sense of disgust, I believe we would also have no sense of the sacred" (Haidt, 2012, pp. 173-174). The shared motivation of to avoid any potential threat of physical and mental contamination makes it likely that people most prone to experience disgust will also render the harshest judgment of purity-related moral transgressions (Haidt, 2012; Haidt \& Graham, 2007; Horberg, Oveis, \& Keltner, 2011; Rozin, Lowery, Imada, \& Haidt, 1999).

This claim that disgust sensitivity relates to moral issues in the purity domain specifically, is consistent with some empirical studies in both moral and political psychology. Individual differences in trait disgust sensitivity predict opposition to gay marriage, abortion, and premarital sex (Inbar et al., 2009; Smith, Oxley, Hibbing, Alford, \& Hibbing, 2011), and people scoring higher on disgust sensitivity have more conservative attitudes towards homosexuality and other threatening or non-traditional sexual practices (Crawford et al., 2014; Inbar, Pizarro et al., 2009; Jarudi, 2009; Olatunji, 2008). These political issues all have been linked with the purity domain (Koleva, Graham, Haidt, Iyer, \& Ditto, 2012). More directly, Horberg and colleagues (2009) find that while disgust sensitivity is positively related to punishment of purity transgressions, it has no such relation to punishment of justice transgressions. These studies support the possibility that disgust sensitivity is most strongly related to moral judgments in the purity domain compared to all of the other moral domains.

Primarily Binding Hypothesis. The primarily binding hypothesis is less specific than the first hypothesis and predicts that disgust sensitivity is a better predictor of judgments of all 
the binding moral domains than of judgments of the individualizing moral domains. There are at least three reasons for making this prediction. First, the binding domains are focused on increasing social cohesiveness and social order, and moral cognition in these domains is correlated with a preference for intuitive and emotional thinking (Garvey \& Ford, 2014). Garvey and Ford also find that the individualizing moral domains (i.e., domains that concern the protection of the individual against harm and injustice) are more strongly related to a preference for rational thinking. More directly, they find that disgust sensitivity is correlated with support for moral values in all three binding moral domains, but not to moral values in any of the individualizing moral domains. Although this provides some indication that disgust sensitivity might be correlated more strongly to moral judgments of the binding moral domains, moral values do not correspond perfectly to moral judgments of specific situations (e.g., endorsing the moral principle of 'do no harm' does not mean that there are no instances in which inflicting some harm is permissible; Clifford, Iyengar, Cabeza, Sinnott-Armstrong, 2015). It should therefore be tested if disgust sensitivity has a similar relation to moral judgments tapping into the binding moral domains.

Second, disgust sensitivity has been associated with maintaining a clear separation between the in-group and out-groups. The idea is that, evolutionarily speaking, out-groups provide a threat of disease that people who are disgust sensitive are particularly tuned for. People who score high on disgust sensitivity then may be more concerned with moral issues and judgments that help to bind the in-group together and maintain separation from out-groups. Consistent with this idea, Naverrete and Fessler (2006) show that higher scores on disgust sensitivity relate not only to more negative perceptions of an out-group, but also to more positive perceptions of the in-group. Furthermore, disgust sensitivity predicts one's stance on issues 
related to in-group protection, such as immigration, and attitudes towards foreign and socially deviant groups (Brenner \& Inbar, 2014; Hodson \& Costello, 2007). More disgust sensitive people agree more with statements such as "immigrants are a threat to our society" and “immigrants bring more crime", and are also more in favor of severe punishments for criminal offenders (Brenner \& Inbar, 2014).

Third, disgust sensitivity has been associated with overall support for political conservative ideologies and belief systems (Inbar, Pizarro, Iyer, \& Haidt, 2012; Terrizzi, Shook, \& Ventis, 2010; Tybur et al., 2016). The binding moral domains are the domains most clearly associated with conservatism (Graham et al., 2009). If disgust sensitivity is associated with more conservative moral judgments overall, then it should be related to harsher judgments across the three binding domains as well.

Considering all these findings, it is surprising that no study yet has directly compared disgust sensitivity's association with moral judgments in each of the binding moral domains. As described above, previous research did show that disgust sensitivity's association with purity judgments is stronger than its association with judgments of individualizing moral domains (i.e., Horberg et al., 2009), but this finding would also be in line with predictions following from a primarily binding hypothesis as it cannot distinguish a purity domain specific effect from a binding domain specific effect. Therefore a study that includes multiple binding domains is necessary to distinguish between the primarily purity hypothesis and the primarily binding hypothesis.

Equal Strength Hypothesis. The most general hypothesis is the equal strength hypothesis, which predicts that disgust sensitivity relates to moral judgments in all domains equally. Admittedly, there is less support for this particular hypothesis, but it is hinted at by 
several perspectives. For example, constructivist perspectives on emotions suggest that emotions are not specifically tied to moral transgressions in any specific domain (Cameron et al., 2015). In a reanalysis of Hofmann and colleagues' (Hofmann, Wisneski, Brandt, \& Skitka, 2014) data, Cameron and colleagues (2015) found that people experience as much disgust in response to purity transgressions as in response to harm transgressions. More directly, Chapman and Anderson (2014) have found that disgust sensitivity relates positively to condemnation of care transgressions, one of the individualizing moral domains. In addition, it has been found that more disgust sensitive participants are more likely to judge a suspect as guilty and, subsequently, propose harsher sentences (Jones \& Fitness, 2008). Importantly, this latter study found no differences for disgusting compared to non-disgusting crimes. The key idea uniting all of these findings is that disgust is negative input into the moral judgment process and so, in turn, leads to harsher moral judgments regardless of the domain (Brandt \& Reyna, 2011; Clore \& Palmer, 2009).

\section{The Current Studies}

We present five studies in which we investigated the domain specificity of the relation between disgust sensitivity and moral judgment, by testing the three mutually exclusive hypotheses described above. Distinguishing between these three hypotheses will help lend support for theories in moral psychology that emphasize the importance (e.g., Graham et al., 2012) or the paucity (e.g., Gray, Young, \& Waytz, 2012) of moral domains.

One downside of moral judgment research is that researchers typically use unstandardized and ad hoc scenarios with unknown validity (e.g., Schnall et al., 2008; Wheatley \& Haidt, 2005). This makes it difficult for researchers to test for the effects of emotions on moral judgments across domains (Clifford et al., 2015; Horberg et al., 2009). Therefore, we use moral 
judgments drawn from the Moral Foundations Vignettes (Clifford et al., 2015). This set of vignettes provides a standardized and validated set of moral judgments that spans much of the moral domain as proposed by Moral Foundations Theory, thereby solving common problems resulting from using unstandardized scenarios.

\section{Studies 1-4}

In four similar studies, we tested the relationship between disgust sensitivity and moral judgments. These data were originally collected for other purposes ${ }^{1}$, but can be used to provide an initial test of the three competing hypotheses. In Study 1 and Study 2 we included a measure of trait anger (Spielberger, 1999) and were able to use this to test if the effects we observe are specific to disgust.

\section{Method}

The four studies were similar in design, so they are described together and deviations are highlighted. In all studies, disgust sensitivity was measured with the 27-item Disgust Sensitivity Scale-Revised (DS-R; Haidt et al., 1994, modified by Olatunji et al., 2007). The first 14 items are answered on a 5-point scale ranging from $0=$ 'Strongly disagree (very untrue about me)' to $4=$ 'Strongly agree (very true about me)'. An example item is "If I see someone vomit, it makes me sick to my stomach". The remaining 13 items are answered on a 5 -point scale ranging from $0=$ 'Not disgusting at all' to $4=$ 'Extremely disgusting'. An example item of this part of the scale is

\footnotetext{
${ }^{1}$ The exact materials that were used in all studies can be found in the supplemental materials at the Open Science Framework (OSF; Supplemental Materials). Studies 1 to 4 included additional measures of potential moderators (i.e., private body consciousness, emotion regulation strategies) and mediators (i.e., sensitivity to deviance, approach and avoidance strategies) that ultimately did not moderate or mediate the relationships. The data of these studies have not been published elsewhere and can be found at the OSF.
} 
"You see maggots on a piece of meat in an outdoor garbage pail". The scale has two filler items that are excluded from the analyses. See Table 2 for the reliability of this scale and the other scales used in these studies.

In Study 1 and Study 2, individual differences in trait anger were measured with the State-Trait Anger Expression Inventory-2 (STAXI; Spielberger, 1999). The STAXI has been used in previous research related to moral cognition (Horberg et al., 2009; Jones \& Fitness, 2008) and is a well-validated measure of trait anger that relates to a variety of anger and aggression expressions (e.g., Barbour, Eckhardt, Davison, \& Kassinove, 1998; Forgays, Forgays, \& Spielberger, 1997; Wang, Yang, Yang, Wang, \& Lei, 2017; Wittmann, Arce, \& Santisteban, 2008). In the current research, only the 10-item trait anger subscale was used. All questions were answered on a 4-point scale ranging from $1=$ '(Almost) Never' to $4=$ '(Almost) Always'. An example item is 'I have a fiery temper'.

In all studies, moral transgressions were taken from a standardized set of vignettes based on Moral Foundations Theory (Clifford et al., 2015). This measure was chosen as it is the first set of moral judgments that is well-validated. Items are developed based on domain specific characteristics, and were categorized by subjects as belonging to a certain moral domain. Participants could also indicate that an item was not morally wrong, making sure that each transgression is considered to be violating a moral, instead of a social, norm. The authors conducted both exploratory as well as confirmatory factor analyses on moral judgments of these items to ensure that each item is a distinct indicator of a moral domain. Additionally, the moral judgment items in this set are controlled for comprehensibility, frequency of the act, imaginability, and strength of the emotional response they elicit. The set includes moral transgressions from six moral domains: care, fairness, authority, loyalty, liberty, and sanctity 
(which we, for sake of consistency, will refer to as purity from now on). Example items are "you see a woman clearly avoiding sitting next to an obese woman on the bus" (care domain) and "you see a story about a remote tribe eating the flesh of their deceased members" (purity domain). Participants indicated for each moral transgression how immoral they found the behavior on a scale ranging from $1=$ 'Not at all immoral' to $7=$ 'Extremely immoral', unless specified otherwise. The number of moral transgressions and the number of moral domains they represent vary across studies.

Study 1. Eighty Dutch students (58 females, $\left.M_{\text {age }}=19.55, S D=1.48\right)$ participated in this study, as part of a series of studies, in return for course credit. They first filled out the disgust sensitivity scale and then provided judgments of eight moral transgressions, equally divided over four moral domains: purity, authority, care, and fairness.

Study 2. Participants were recruited via social media and online fora. Two-hundred twenty-one Dutch participants completed the entire questionnaire (171 females, 48 males, 2 unknown, $M_{\text {age }}=31.45, S D=13.92$ ). Participants first filled out the disgust sensitivity scale and then proceeded with the moral judgments. Participants not only indicated how immoral they found each transgression, but they also indicated to what extent they would like to punish the person for his/her behavior $(1=$ 'Not at all' to $7=$ 'Very much so'). Participants made these judgments for ten transgressions from different moral domains; three purity items, two authority items, three care items, and two fairness items.

Study 3. Two-hundred and four Dutch students ( 161 females, $\left.M_{\mathrm{age}}=19.43, S D=1.86\right)$ participated in this study, as part of a series of studies, in return for course credit. They filled out the disgust sensitivity scale and rated the same ten moral transgressions on immorality as in Study 2. 
Study 4. One-hundred and forty-eight Dutch students (119 females, $M_{\text {age }}=19.97, S D=$ 2.29) were recruited on campus and participated voluntarily in this study. The disgust sensitivity scale was filled out first followed by eight moral transgressions: four purity, two care, and two fairness items.

\section{Results and Discussion}

Primary Analyses. Path analysis was used to estimate and compare the strength of the relationship between disgust sensitivity and judgments of moral transgressions of all the moral domains. These analyses were conducted using the 'sem' function in the 'lavaan' package of $\mathrm{R}$ (Rosseel, 2012). See Table 2 for an overview of means, standard deviations, and correlations between all subscales described in this section.

First, a free model including disgust sensitivity as a predictor and all moral domains as outcome variables was fitted. ${ }^{2}$ The unstandardized estimates from this model per dataset are in Figure 1. It appears that across the four samples disgust sensitivity is a stronger predictor of immorality and punishment ratings of purity transgressions than ratings of transgressions in the other domains. Similarly, the other binding domain (i.e., authority) looks approximately equal in strength to the individualizing domains. These initial impressions are consistent with the primarily purity hypothesis, but not with the equal strength or the primarily binding hypotheses.

To test these impressions, we next compared the free model with the "all equal" model in which all paths between disgust sensitivity and the moral domains are constrained to be equal. Chi-square tests show that the all equal model fits the data significantly worse than the free model in all four studies (see Table 3). This suggests that there are significant differences in the strength of the paths depending on the moral domain. To directly assess the validity of the

\footnotetext{
${ }^{2}$ This is a saturated model, therefore, no fit indices are reported for this model.
} 
primarily binding and primarily purity hypotheses we compared the free model to models in which pairs of paths between disgust sensitivity (DS) and judgments in one of the moral domains are constrained to be equal (see Table 3 for hypothesis-relevant constraints).

The primarily purity hypothesis predicts that constraining the DS-purity link to be equal to any of the other DS-moral domain links will result in poorer fit as a result of a stronger DSpurity association. Consistent with this hypothesis, across 13 of the 14 relevant model comparisons the constraint significantly hurt model fit. In the remaining relevant comparison (in Study 4 where the DS-purity link is compared to the DS-care link), the effect was in the direction consistent with the primarily purity hypothesis, but the constraint was not significant $(p=.09)$.

The primarily binding hypothesis is an expanded version of the primarily purity hypothesis. It also predicts that the DS-purity link will be stronger than the DS-care and DSfairness links; however, it differs in that it predicts that the DS-authority link will be larger than the DS-care and the DS-fairness links as well and similar in size to the DS-purity link. The prior paragraph showed that the DS-authority link was never similar in strength to the DS-purity link. The additional comparisons between the DS-authority link and both DS-fairness and DS-care links were not any more supportive of the hypothesis. Three of the eight constraints significantly hurt model fit, but were in the opposite direction of the predictions following from the primarily binding hypothesis (e.g., the DS-authority link is significantly weaker than the DS-care link in Study 4). Only one of the eight constraints significantly hurt model fit and was in the expected direction (i.e., the DS-authority link is significantly different from the DS-fairness link in Study 2); however, the DS-authority link in this case did not differ from zero. The remaining four constraints did not hurt model fit, showing no difference in strength for these links. The 
primarily binding hypothesis was thus not supported. Overall, the results provide most support for the primarily purity hypothesis.

Additional Analyses. In Study 1 and Study 2 we were able to use the same model comparison approach as just described, but also control for trait anger. See Table 2 for an overview of means and standard deviations of trait anger, and correlations of trait anger with all subscales. To control for trait anger, a model including disgust sensitivity and trait anger as predictors and all moral domains as outcome variables was fitted. Subsequently, the same constraints were applied to the association between disgust sensitivity and moral judgments as described above. Adding trait anger to the models did not change the results of any but two model comparisons. In both cases, adding trait anger to the model affected the comparison between the free model and the model in which the DS-authority and DS-fairness links were constraint to be equal. In Study 1, the initial model comparison showed that the DS-authority and DS-fairness links did not differ in strength, but when controlling for trait anger, the DS-authority link was found to be significantly stronger than the DS-fairness link $\left(\chi^{2}[1, N=80]=4.41, p=\right.$ .04). However, for the punishment data in Study 2 the exact opposite happened when controlling for trait anger. While the DS-authority link was initially stronger than the DS-fairness link, including trait anger made both links equal in strength $\left(\chi^{2}[1, N=221]=3.32, p=.07\right)$. Importantly though, adding trait anger to the models did not change our conclusion that disgust sensitivity is more strongly related to the purity domain than to any of the other moral domains. Because the inclusion of trait anger did not affect our conclusion, we did not include it in our final study. ${ }^{3}$

\section{Study 5}

\footnotetext{
${ }^{3}$ See Supplemental Materials for all model comparisons, with and without controlling for trait anger.
} 
In the first four studies, we found that disgust sensitivity is more strongly associated with purity moral judgments than to moral judgments in the authority, care, and fairness domains. This provides support for the primarily purity hypothesis and contradicts the equal strength and primarily binding hypotheses. However, these findings might be related to the specifics of the studies. For example, purity judgments tended to have higher reliability than judgments in other domains (e.g., care in Study 4). The low reliabilities may be due to the characteristics of our particular samples (i.e., from The Netherlands) compared to the samples used to create the stimuli (i.e., from the United States; Clifford et al., 2015) or because we used a relatively small number of moral judgments. Another constraint of our studies is that we only included one other binding moral domain (authority) in addition to purity. It may be the case that loyalty moral judgments, the third binding moral domain, are also particularly strongly associated with disgust sensitivity. Disgust and disgust sensitivity have been shown to predict opposition to out-groups in order to protect the in-group from the potential disease threat out-groups are believed to possess (Brenner \& Inbar, 2014; Hodson \& Costello, 2007) and so by not including loyalty judgments we might have overstated our case. We also did not include any judgments regarding liberty or freedom, a domain that people appear to consider moral (e.g., Clifford et al., 2015; Graham et al., 2012; Haidt, 2012; Hoffman et al., 2014; Iyer, Koleva, Graham, Ditto, \& Haidt, 2012). Finally, we did not originally set out to test these particular hypotheses with these first four studies and therefore sought out to directly test our hypothesis with more reliable measures of moral judgments across a wider array of moral judgments. This study and our expectation that the primarily purity hypothesis would receive most support was preregistered at the Open Science Framework before data collection started. ${ }^{4}$

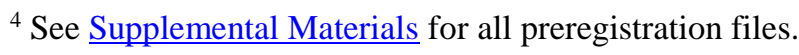




\section{Method}

Participants. Based on the findings in our previous studies, ${ }^{5}$ a conservative a priori power analysis was conducted using G*Power (Faul, Erdfelder, Lang, \& Bucher, 2007) to detect a difference in slope of .158. This suggested that a sample size of 424 participants was necessary to achieve power of $90 \%$. Therefore, we aimed for at least 450 participants, recruited via Amazon Mechanical Turk. In the end, 451 MTurkers (208 females, 242 males, 1 other, $M_{\text {age }}=$ 35.31, $S D=10.66$ ) completed our study in return for a financial reward.

Materials. Disgust sensitivity was measured with the same scale as in Studies 1 to 4 (i.e., DS-R; Haidt et al., 1994, modified by Olatunji et al., 2007). Sixty moral transgressions were taken from the same item set as in Studies 1 to 4 (Clifford et al., 2015), ten from each moral domain. All moral domains had high reliabilities (see Table 2). Participants indicated to what extent they found each moral transgression immoral on a scale ranging from $1={ }^{\text {'Not at all }}$ immoral' to $7=$ 'Extremely immoral'.

\section{Results}

See Table 2 for an overview of means, standard deviations, and correlations between all subscales. Our pre-registered, confirmatory analyses used the same data analytic strategy as in Studies 1 to 4. First, a free model including disgust sensitivity as a predictor and all moral domains as outcome variables was fitted (for the unstandardized estimates, see Figure 1). To test the equal strength hypothesis, we compared the free model with the "all equal" model in which all paths between disgust sensitivity and moral domains are constrained to be equal.

\footnotetext{
${ }^{5}$ This includes the first four studies in this article, plus an additional study that accidently excluded 7 disgust sensitivity items and included repeats of another 7 disgust sensitivity items. We analyzed this data without the repeated items and used the conclusions to inform our power analyses (see Supplemental Materials, Study 5A).
} 
Contradictory to what is expected according to the equal strength hypothesis, a chi-square test shows that the all equal model fits the data significantly worse than the free model, suggesting that some moral domains are significantly stronger related to disgust sensitivity than others (see Table 3). As in Studies 1 to 4, we assessed the validity of the primarily purity and primarily binding hypotheses by comparing the free model to models in which pairs of paths between disgust sensitivity (DS) and judgments in one of the moral domains are constrained to be equal (see Table 3 for hypothesis-relevant constraints).

To test the primarily purity hypothesis, the free model was compared to models in which the DS-purity link is constrained to be equal to each of the other DS-moral domain links. All five alternative models resulted in poorer model fit, showing that the DS-purity link is significantly stronger than any of the other links between disgust sensitivity and one of the moral domains, thereby supporting the primarily purity hypothesis.

The primarily binding hypothesis predicts that the DS-purity, DS-authority, and DSloyalty links will be stronger than the DS-care, DS-fairness, and DS-liberty links. Although the previous paragraph already showed that the DS-purity link is stronger than both the DS-authority and DS-loyalty links, we continued to test support for the primarily binding hypothesis by comparing the additional relevant paths for the DS-authority and DS-loyalty links. Four of these six constraints indeed significantly hurt model fit in the expected direction. The DS-authority and DS-loyalty links were significantly stronger than the DS-fairness and DS-liberty links. However, contrary to the primarily binding hypothesis, constraining the DS-authority and DS-loyalty link to be equal to the DS-care link did not significantly hurt model fit, suggesting they are equal in strength. The primarily binding hypothesis is therefore not fully supported. In line with Studies 1 
to 4 and in line with our preregistered expectations, most support was found for the primarily purity hypothesis. ${ }^{6}$

\section{Internal Meta-Analysis}

An internal meta-analysis was conducted to analyze the association between disgust sensitivity and purity moral judgments, as compared to the other moral domains, across all our studies. The meta-analysis was conducted using the 'rma' function in the 'metafor' package of $\mathrm{R}$ (Viechtbauer, 2010). For all studies, the correlations between disgust sensitivity and judgments in all the moral domains were included using Fisher $r$-to- $z$ transformations. In addition to the five studies above, we also included an additional study where we accidently excluded 7 disgust sensitivity items and included repeats of another 7 disgust sensitivity items (see Footnote 5). We analyzed this data without the repeated items (see Supplemental Materials, Study 5A) to include it in the meta-analysis. The correlations related to the punishment judgments of Study 2 were not included because these items do not have multiple measurements across our studies.

A fixed-effects model confirms that there is a significant relation between disgust sensitivity and moral judgments across all of the moral judgments $(r=.26, p<.001)$. To test the equal strength hypothesis, moral domain was added to the model as a moderator. Contrary to what the equal strength hypothesis would predict, moral domain moderates the effect $\left(\mathrm{Q}_{\mathrm{M}}[5]=\right.$ 86.796, $p<.001$ ), showing that the strength of the effect differs depending on type of moral domain.

\footnotetext{
${ }^{6}$ We conducted an exploratory test of political ideology as a mediator between disgust sensitivity and moral judgments of purity. While we replicated the pattern reported by Clifford and colleagues (2015) regarding the relation between political ideology and each of the moral domains, we find no relation between political ideology and disgust sensitivity (in line with results reported for pathogen disgust in van Leeuwen et al., 2017).
} 
To test the primarily purity hypothesis, the DS-purity link was taken as the reference category against which all other links were tested. Additionally, country where the study took place was added as a moderator to account for the differences in strength of the relations (i.e., the relation between disgust sensitivity and moral judgments seemed stronger across all moral domains in the US samples than in the Dutch samples). By adding it as a moderator we can control for this. Conclusions remained the same without this moderator added to the model. Consistent with the primarily purity hypothesis, the DS-purity link $(r=.40)$ was found to be significantly stronger than all other links between disgust sensitivity and judgments of moral domains (DS-authority: $r=.19 ; z=-5.95, p<.001$; DS-loyalty: $r=.24 ; z=-4.00, p<.001$; DScare: $r=.27 ; z=-4.08, p<.001$; DS-fairness: $r=.11 ; z=-8.46, p<.001$; DS-liberty: $r=.07 ; z=$ $-7.66, p<.001)$.

Next, we tested the primarily binding hypothesis that disgust sensitivity is more strongly related to moral judgments in the binding domains (i.e., purity, authority, and loyalty) than in the individualizing domains (i.e., care, fairness, and liberty). The previous paragraph shows that the DS-purity link is stronger than any other DS-moral domain links, regardless of whether the domain is classified as individualizing or binding. To test whether the DS-authority link is stronger than the link between disgust sensitivity and the individualizing moral domains, the DSauthority link was taken as the reference category. Controlling for country, the DS-authority link proved to be significantly stronger than both the DS-fairness $(z=-2.16, p=.03)$ and DS-liberty $(z=-2.62, p=.009)$ links, but significantly weaker than the DS-care link $(z=2.04, p=.04)$. Taking the DS-loyalty link as the reference category revealed a similar pattern. The DS-loyalty link proved to be significantly stronger than both the DS-fairness $(z=-2.81, p=.005)$ and DSliberty $(z=-3.33, p<.001)$ links, but equal in strength to the DS-care link $(z=0.71, p=.48)$. 
The primarily binding hypothesis was thus not fully supported. Again, most support was found for the primarily purity hypothesis.

\section{General Discussion}

The relation between individual differences in disgust sensitivity and attitudes related to the moral domain is well established (e.g., Crawford et al., 2014; Inbar et al., 2009; Jones \& Fitness, 2008; Naverrete \& Fessler, 2006). A question that remained unanswered, however, is whether this association between disgust sensitivity and morality is general or if it is specific to a certain set of moral domains. We derived three plausible hypotheses from the literature. The primarily purity hypothesis states that disgust sensitivity is more strongly related to moral judgments in the purity domain than to moral judgments in any of the other moral domains. The primarily binding hypothesis takes a somewhat broader perspective by distinguishing binding from individualizing moral domains and predicts that disgust sensitivity is primarily related to judgments in the binding moral domains. The last and most general hypothesis, the equal strength hypothesis, however, predicts that disgust sensitivity relates to moral judgments across all domains equally.

In five studies, including one pre-registered study, and an internal meta-analysis, we tested these hypotheses against each other and found strong support for the primarily purity hypothesis. In both Dutch and American samples, we find that disgust sensitivity is more strongly related to moral judgments of purity transgressions than to moral judgments of transgressions of any other domain. No convincing support was found for the equal strength or primarily binding hypothesis.

These findings are in line with Moral Foundations Theory, which argues that differences in moral sensitivity to each domain can be dependent on an individual's personality (Graham et 
al., 2012). The general idea is that specific personality traits make specific problems in our surroundings salient, and over time, these types of problems become the focus of our moral concern. In our case, the personality trait of disgust sensitivity seems to make an individual especially concerned with transgressions of moral purity.

\section{A Permissive Equal Strengths Hypothesis}

Although these findings are not supportive of the equal strength hypothesis as we defined it, we should note that not everyone might agree with the strict perspective we took of this account. A more permissive version of this hypothesis might predict that disgust sensitivity does not relate to one moral domain specifically and so correlations might be found with other domains, no matter their strength. Without the restriction that all moral domains have an equally strong relationship with disgust sensitivity, this account would receive more support. For example, one could point to the significant correlations between disgust sensitivity and moral judgments of the care and authority domain in Study 5 and interpret these as evidence in favor of this permissive version of the equal strength hypothesis. However, we believe that such an account has two major drawbacks. First, this version of the equal strengths hypothesis has very little predictive power. It does not identify which moral domains should or should not correlate with certain personality characteristics and it does not specify a sufficiently strong correlation to "count" as evidence in support of the hypothesis. For example, if we found a significant correlation between disgust sensitivity and non-purity judgments that was a very small $r=.05$, would that be consistent with an equal strengths hypothesis? This seems too permissive to be useful. Second, even when putting aside this shortcoming, the evidence for such an account is, according to our data, weak at best. Although we identified some significant correlations between non-purity domains and disgust sensitivity in our studies, they do not appear 
consistently across all of our studies. For example, disgust sensitivity is not significantly related to moral judgments in the authority domain in Studies 1, 2, and 3, nor to the moral judgments of the care domain in Studies 1 and 2. We therefore conclude that, even when taking into account a more permissive version of the equal strength hypothesis, our data fit the primarily purity hypothesis best.

\section{Moral Foundations Vignettes vs. Moral Foundations Questionnaire}

Certainly, we are not the only ones to have proposed and tested such a link between disgust and moral purity (e.g., Crawford et al., 2014; Horberg et al., 2009; Inbar, Pizarro, \& Bloom, 2009; Inbar, Pizarro et al., 2009; Jarudi, 2009; Olatunji, 2008; Rozin et al., 1999; Smith et al., 2011). Recently, van Leeuwen and colleagues (2017) demonstrated that trait pathogen disgust is related to moral purity measured by the Moral Foundations Questionnaire (MFQ). While their research might look similar at face value, we think that there are some important distinctions that should be highlighted. One distinction is that the MFQ and the Moral Foundations Vignettes (MFV), used in our studies, measure distinct components of morality. While the MFQ focuses on the relevance of abstract moral concerns, the MFV is set up to test moral judgments of specific behaviors and situations. Moral judgments, as compared to measures of abstract moral concerns, are important outcomes because they allow for the impact of moral intuitions and form the basis of one of the criteria determining the existence of a moral domain (see Introduction). Even though the second half of the MFQ are said to include moral judgment items, it can be doubted to what degree these actually assess moral condemnation (i.e., disagreeing with items such as "I am proud of my country's history" does not necessarily imply that the participant thinks it is morally wrong to be proud of your country's history) and most items still focus on endorsement of abstract situations or values (e.g., "I would call some acts 
wrong on the grounds that they are unnatural"). Although it is likely that such broad moral concerns inform moral judgments of specific situations, Graham and colleagues (2012, p. 1031) agree that the MFQ "does not necessarily measure how people actually make moral judgments". Importantly, correlations between the MFV and MFQ are indeed small to medium, which is not surprising since studies show that people express different degrees of moral concern depending on situation specific characteristics (e.g., Crimston, Bain, Hornsey, \& Bastian, 2016; Cushman, Young, \& Hauser, 2006). We believe that the most crucial contribution of our research, though, concerns disgust sensitivity's relative relation to each of the moral domains. Although previous studies have shown a link between disgust sensitivity and the purity domain, none of these have systematically compared the strength of disgust sensitivity's relation across each of the moral domains.

\section{Possible Mechanisms}

Although our data reveal overwhelming support for the primarily purity hypothesis, it remains to be tested what psychological mechanism accounts for this relation.

Behavioral Immune System. One potential mechanism that has been suggested is the close involvement of the behavioral immune system in the experience of both pathogen disgust and moral transgressions of the purity domain (Inbar \& Pizarro, 2014). Purity transgressions often include potential contagion threats (e.g., via unusual foods or sexual practices) ${ }^{7}$ to which

\footnotetext{
${ }^{7}$ Please note that the Disgust Sensitivity Scale - Revised (DS-R) includes only 1 item referring to sex. Removing this item from the DS-R did not affect any of the model comparisons reported in our studies. Similarly, the DS-R relates as strongly to purity transgressions referring to sexual activities (6 items) as to purity transgressions without such a reference (4 items; both $r$ 's are .39). Conducting the analyses without these 6 items did not affect any of the model comparisons reported in Study 5
} 
more disgust sensitive people are more likely to respond with rejection and avoidance (Inbar \& Pizarro, 2014).

A similar, but less generous explanation results from an ongoing debate on what exactly constitutes the purity domain. More specifically, it has been argued that disgust sensitivity’s unique relation with purity judgments is not related to moral content, but instead is caused by general features of purity scenarios, such as direct references to core disgust elicitors (e.g., Cameron et al., 2015). However, we have two reasons to believe that such an explanation cannot account for the effects found in our studies. First, the moral transgressions that were used in our studies do not make direct references to core disgust eliciting stimuli such as bodily fluids). Second, even if this would be the case, in two additional studies we find that the presence of a core disgust elicitor in a moral transgression is not sufficient to establish a strong connection to disgust sensitivity. In these studies, including a student sample $(N=144)$ and a sample from the general population $(N=190)$, we tested whether adding a pathogen cue to non-purity moral transgressions results in a stronger relationship with disgust sensitivity (e.g., a burglar dropping ink on the carpet vs a burglar urinating on the carpet). However, disgust sensitivity does not relate to any of the moral judgments in our studies, regardless of the presence of pathogen cues (for all main effects of disgust sensitivity and all interactions between disgust sensitivity and condition, $t$ 's $<1.34, p$ 's $>.18$ ). On the contrary, examining the data using Bayesian analyses (in which the fit of the data under the alternative hypothesis is compared to the fit of the data under the null hypothesis; Morey \& Rouder, 2014) returned a Bayes factor of, on average, 0.425 (ranging between 0.293 and 0.712 ) in favor of the null hypothesis. In other words, our data were almost 2.5 times more likely to occur under the model that predicts no interaction effect of disgust sensitivity and the presence (vs. absence) of a pathogen cue on moral judgments than 
under the model predicting such an interaction effect (for more information on these studies, see Supplemental Materials). We therefore think it is unlikely that the potential presence of core disgust elicitors in purity transgressions alone accounts for the relationship between disgust sensitivity and purity moral judgments.

Weird Scenarios. An alternative mechanism that might be at play concerns the weirdness of moral scenarios often featured in the purity domain. Popular scenarios tapping into the purity domain are perceived to be weirder (i.e., more abnormal) than scenarios measuring the care domain (Chakroff \& Young, 2015; Gray \& Keeney, 2015). According to Gray and Keeney (2015) this "weirdness may also help account for the oft-discussed link between disgust and impurity [..], without referencing distinct moral mechanisms". Although there is yet no empirical evidence supporting this claim, it could be that individuals who are more easily disgusted are more sensitive to any kind of deviation from what is normal, and thus also to these weird or bizarre scenarios representing the purity domain. As one preliminary test of this idea, we included an abstract measure of sensitivity to deviation (Okimoto \& Gromet, 2016) in Study 4. However, this measure was not correlated with disgust sensitivity $(r[148]=-.05, p=.58)$ or purity moral judgments $(r[148]=-.08, p=.32)$.

Moral Character. A related fourth potential mechanism is moral character. Recent evidence suggests that disgust is sensitive to evidence of a person's moral character (GinerSorrola \& Chapman, 2016). People might be especially likely to use actions that are particularly abnormal, as Gray and Keeney (2015) argue purity transgressions are, as indicators of a person's moral character (Tannenbaum, Uhlmann, \& Diermeier, 2011). If disgust sensitivity also indexes an interest and sensitivity to moral character, this may also help to explain the primarily purity hypothesis. 


\section{Disgust Sensitivity Measure}

One potential limitation of our studies is that we use the same scale to measure disgust sensitivity in all five of our studies (i.e., DS-R; Haidt et al., 1994, modified by Olatunji et al. 2007). Although this is the most widely used measure of disgust sensitivity, some might argue it is based on an incomplete definition of disgust. The Three Domain Disgust Scale (TDDS; Tybur et al., 2009), for example, includes not only pathogen disgust, but also sexual and moral disgust. However, because the TDDS is highly correlated with all subscales of the DS-R (Tybur et al., 2009) it is likely that using this measure of disgust sensitivity would yield results similar to our current findings. In line with that reasoning, Van Leeuwen and colleagues (2017) find that the pathogen subscale of the TDDS has a high correlation with moral values of purity $(r=.31)$, relative to correlations with moral values of authority $(r=.24)$, loyalty $(r=.19)$, care $(r=.20)$, and fairness $(r=.12)$. In addition, there is substantial overlap between the two additional subscales of the TDDS (i.e., sexual disgust and moral disgust) and specific moral domains. While the sexual disgust scale relates closely to moral transgressions in the purity domain (i.e., including items related to promiscuity and specific sexual acts), the moral disgust subscale is compatible with moral transgressions of fairness and care (i.e., including items related to theft and dishonesty). It is therefore not surprising, and consistent with our findings, that the pathogen disgust subscale is strongly correlated with the sexual disgust subscale (i.e., purity transgressions; $r=.38$; Tybur et al., 2009, Study 4) and less so with the moral disgust subscale (i.e., fairness and care transgressions; $r=.17$; Tybur et al., 2009, Study 4).

\section{Are Moral Domains Distinct Constructs?}

Lastly, we want to address the discussion on whether the moral domains suggested by Moral Foundations Theory measure distinct constructs (e.g., Gray, Waytz, \& Young, 2012). 
Contra Moral Foundations Theory, some have argued that the moral foundations are not distinct domains and instead are all manifestations of a single underlying domain (e.g., typically harm; Gray et al., 2012; Cameron et al., 2015). Although our paper aimed to distinguish between hypotheses about the association between disgust sensitivity and moral judgments across domains, our question and its answers have implications for this broader debate. For example, one could point to the relatively high correlations between moral domains in some of our studies (see especially Study 5, see Table 2) and use this to argue that all moral judgments stem from a single domain. However, these correlations - and even if they were stronger - would not provide reliable evidence in favor of the existence of one common construct.

There are several reasons. First, these high correlations were not a feature of every study, suggesting that a single domain account cannot parsimoniously describe the pattern of correlations across all of our studies. Second, prior validity testing and factor analyses by Clifford and colleagues (2015) has shown that all transgressions are reflective of distinct moral concerns. Third, and conceptually more consequential, even if scales are highly correlated that does not preclude that the scales measure different constructs. The idea that all moral domains can be reduced to one underlying construct implies that these scales are highly correlated because they share a common latent variable that causes participants' responses on the scales. Such a model assumes that the scales share common causes, consequences, and correlates. If scales have different causes, consequences, and correlates then they do not share the same latent variable (see also statistical vs. causal uni-dimensionality, Markus \& Borsboom, 2013, p. 148149). Research on attitude strength illustrates this idea very clearly. While some indicators of attitude strength are highly correlated, there is robust evidence that they have unique causes and correlates, therefore demonstrating that they are unique (but correlated) constructs (e.g., Visser, 
Bizer, \& Krosnick, 2006; Krosnick, Boninger, Chuang, Berent, \& Carnot, 1993). If the different moral domains would actually measure only one construct, all domains should have common correlates and the results should have favored the equal strength hypothesis. However, our studies did not favor this hypothesis. Instead, our studies consistently found a stronger relationship between disgust sensitivity and the purity domain. This finding in itself is an argument against the claim that these domains are all based on a common construct.

\section{Conclusion}

A key task for understanding taxonomies of the moral domain is how judgments in these different domains are similar and different. One area where some scholars expect differences and where others claim similarities are the traits and emotions that are linked with judgments across the moral domains. By purposefully investigating disgust sensitivity as it relates to several moral domains, our data add and speak to this broader debate. We find that although making moral judgments is an emotional process, the tendency to feel disgust is not consistently related to types of moral judgments. Instead, as suggested by domain-centric theories like Moral Foundations Theory, disgust sensitivity is primarily associated with moral judgments in the purity domain. 


\section{References}

Barbour, K. A., Eckhardt, C. I., Davison, G. C., \& Kassinove, H. (1998). The experience and expression of anger in maritally violent and nonviolent men. Behavior Therapy, 29, 173191. doi:10.1016/S0005-7894(98)80001-4

Borg, J. S., Lieberman, D., \& Kiehl, K. A. (2008). Infection, incest, \& iniquity: Investigating the neural correlates of disgust and morality. Journal of Cognitive Neuroscience, 20, 15291546. doi: 10.1162/jocn.2008.20109

Brandt, M. J., \& Reyna, C. (2011). The chain of being: A hierarchy of morality. Perspectives on Psychological Science, 6, 428-466. doi:10.1177/1745691611414587

Brenner, C. J., \& Inbar, Y. (2014). Disgust sensitivity predicts political ideology and policy attitudes in the Netherlands. European Journal of Social Psychology, 45, 27-38.

doi:10.1002/ejsp.2072

Cameron, C. D., Lindquist, K. A., \& Gray, K. (2015). A constructionist review of morality and emotions: No evidence for specific correspondences between discrete emotions and moral concerns. Personality and Social Psychology Review, 19, 371-394. doi:10.1177/1088868314566683

Cannon, P. R., Schnall, S., \& White, M. (2011). Transgressions and expressions: Affective facial muscle activity predicts moral judgments. Social Psychological and Personality Science, 2, 325-331. doi:10.1177/1948550610390525

Chakroff, A., \& Young, L. (2015). Harmful situations, impure people: An attribution asymmetry across moral domains. Cognition, 136, 30-37. doi:10.1016/j.cognition.2014.11.034 
Chapman, H. A., \& Anderson, A. K. (2014). Trait physical disgust is related to moral judgments outside of the purity domain. Emotion, 14, 341-348. doi:10.1037/a0035120

Chapman, H. A., Kim, D. A., Susskind, J. M., \& Anderson, A. K. (2009). In bad taste: Evidence for the oral origins of moral disgust. Science, 323, 1222-1226. doi:10.1126/science. 1165565

Clifford, S., Iyengar, V., Cabeza, R., \& Sinnott-Armstrong, W. (2015). Moral foundations vignettes: A standardized stimulus database of scenarios based on moral foundations theory. Behavior Research Methods, 47, 1178-1198. doi:10.3758/s13428-014-0551-2

Clore, G. L., \& Palmer, J. E. (2009). Affective guidance of intelligent agents: How emotion controls cognition. Cognitive Systems Research, 10, 21-30. doi:10.1016/j.cogsys.2008.03.002

Crawford, J., Inbar, Y., \& Maloney, V. (2014). Disgust sensitivity selectively predicts attitudes towards groups that threaten (or uphold) traditional sexual morality. Personality and Individual Differences, 70, 218-223. doi:10.1016/j.paid.2014.07.001

Crimston, D., Bain, P. G., Hornsey, M. J., \& Bastian, B. (2016). Moral expansiveness: Examining variability in the extension of the moral world. Journal of Personality and Social Psychology, 111, 636-653. doi: 10.1037/pspp0000086

Curtis V., \& Biran A. (2001). Dirt, disgust, and disease: Is hygiene in our genes? Perspectives in Biology and Medicine, 44, 17-31. doi:10.1353/pbm.2001.0001 
Cushman, F. A., Young, L., \& Hauser, M. D. (2006). The Role of Conscious Reasoning and Intuition in Moral Judgments: Testing three principles of harm. Psychological Science 17, 1082-1089. doi:10.1111/j.1467-9280.2006.01834.x

Darwin, C. (1872). The expression of the emotions in man and animals. London: John Murray. doi: 10.1037/10001-000

De Jong, P. J., \& Merckelbach, H. (1998). Blood-injection-injury phobia and fear of spiders: Domain specific individual differences in disgust sensitivity. Personality and Individual Differences, 24, 153-158. doi:10.1016/S0191-8869(97)00178-5

Druschel, B. A., \& Sherman, M. F. (1999). Disgust sensitivity as a function of the Big Five and gender. Personality and Individual Differences, 26, 739-148. doi:10.1016/S01918869(98)00196-2

Duncan, L. A., Schaller, M., \& Park, J. H. (2009). Perceived vulnerability to disease: Development and validation of a 15 -item self-report instrument. Personality and Individual Differences, 47, 541-546. doi:10.1016/j.paid.2009.05.001

Faul, F., Erdfelder, E., Lang, A.-G., \& Buchner, A. (2007). G*Power 3: A flexible statistical power analysis program for the social, behavioral, and biomedical sciences. Behavior Research Methods, 39, 175-191. doi:10.3758/BF03193146

Forgays, D. G., Forgays, D. K., \& Spielberger, C. D. (1997). Factor structure of the State-Trait Anger Expression Inventory. Journal of Personality Assessment, 69, 497-507. doi:10.1207/s15327752jpa6903_5 
Garvey, K. J., \& Ford, T. G. (2014). Rationality, political orientation, and the individualizing and binding moral foundations. Letters on Evolutionary Behavioral Science, 5, 9-12. doi:10.5178/lebs.2014.2910.5178/lebs.2014.29

Giner-Sorolla, R., \& Chapman, H. (2016). Beyond purity: Moral disgust toward bad character. Psychological Science, 28, 80-91. doi:10.1177/0956797616673193

Graham, J., Haidt, J., Koleva, S., Motyl, M., Iyer, R., Wojcik, S., \& Ditto, P. H. (2012). Moral Foundations Theory: The pragmatic validity of moral pluralism. Advances in Experimental Social Psychology, 47, 55-130. doi:10.1016/B978-0-12-407236-7.00002-4

Graham, J., Haidt, J., \& Nosek, B. A. (2009). Liberals and conservatives rely on different sets of moral foundations. Journal of Personality and Social Psychology, 96, 1029-1046.

doi:10.1037/a0015141

Graham, J., Nosek, B. A., Haidt, J., Iyer, R., Koleva, S., \& Ditto, P. H. (2011). Mapping the moral domain. Journal of Personality and Social Psychology, 101, 366-385.

doi:10.1037/a0021847

Gray, K., \& Keeney, J. E. (2015). Impure, or just weird? Scenario sampling bias raises questions about the foundation of morality. Social Psychological and Personality Science, 6, 859 -868. doi:10.1177/1948550615592241

Gray, K., Young, L., \& Waytz, A. (2012). Mind perception is the essence of morality. Psychological Inquiry, 23, 101-124. doi:10.1080/1047840X.2012.651387 
Gray, K., Waytz, A., \& Young, L. (2012). The moral dyad: A fundamental template unifying moral judgment. Psychological Inquiry, 23, 206-215. doi:10.1080/1047840X.2012.686247

Haidt, J. (2001). The emotional dog and its rational tail: A social intuitionist approach to moral judgment. Psychological Review, 108, 814-834. doi:10.1037//0033-295X. 108.4.814

Haidt, J. (2008). Morality. Perspectives on Psychological Science, 3, 65-72.

doi:10.1111/j.1745-6916.2008.00063.x

Haidt, J. (2012). The righteous mind: Why good people are divided by politics and religion. New York: Pantheon.

Haidt, J., \& Graham, J. (2007). When morality opposes justice: Conservatives have moral intuitions that liberals may not recognize. Social Justice Research, 20, 98-116. doi:10.1007/s11211-007-0034-z

Haidt, J., \& Joseph, C. (2007). The moral mind: How 5 sets of innate moral intuitions guide the development of many culture-specific virtues, and perhaps even modules. In P. Carruthers, S. Laurence, \& S. Stich (Eds.) The Innate Mind, Vol. 3 (pp. 367-391). New York: Oxford.

Haidt, J., \& Kesebir, S. (2010). Morality. In S. Fiske, D. Gilbert, \& G. Lindzey (Eds.) Handbook of Social Psychology, $5^{\text {th }}$ Edition (pp. 797-832). Hobeken, NJ: Wiley.

Haidt, J., McCauley, C., \& Rozin, P. (1994). Individual differences in sensitivity to disgust: A scale sampling seven domains of disgust elicitors. Personality and Individual Differences, 16, 701-713. doi:10.1016/0191-8869(94)90212-7 
Haidt, J., Rozin, P., McCauley, C., \& Imada, S. (1997). Body, psyche, and culture: The relationship of disgust to morality. Psychology and Developing Societies, 9, 107-131. doi:10.1177/097133369700900105

Hodson, G., \& Costello, K. (2007). Interpersonal disgust, ideological orientations, and dehumanization as predictors of intergroup attitudes. Psychological Science, 18, 691 -698. doi:10.1111/j.1467-9280.2007.01962.x

Hofmann, W., Wisneski, D. C., Brandt, M. J., \& Skitka, L. J. (2014). Morality in everyday life. Science, 345, 1340-1343. doi:10.1126/science.1251560

Horberg, E. J., Oveis, C., \& Keltner, D. (2011). Emotions as moral amplifiers: An appraisal tendency approach to the influences of distinct emotions upon moral judgment. Emotion Review, 3, 237-244. doi:10.1177/1754073911402384

Horberg, E. J., Oveis, C., Keltner, D., \& Cohen, A. B. (2009). Disgust and the moralization of purity. Journal of Personality and Social Psychology, 97, 963-976. doi:10.1037/a0017423

Inbar, Y. \& Pizarro, D. A. (2014). Pollution and purity in moral and political judgment. In J. C. Wright \& H. Sarkissian (Eds.), Advances in Experimental Moral Psychology: Affect, Character, and Commitments (pp. 111-129). New York: Continuum Press.

Inbar, Y., Pizarro, D. A., \& Bloom, P. (2009). Conservatives are more easily disgusted than liberals. Cognition and Emotion, 23, 714-725. doi:10.1080/02699930802110007 
Inbar, Y., Pizarro, D. A., Iyer, R., \& Haidt, J. (2012). Disgust sensitivity, political conservatism, and voting. Social Psychological and Personality Science, 3, 537-544. doi:10.1177/1948550611429024

Inbar, Y., Pizarro, D. A., Knobe, J., \& Bloom, P. (2009). Disgust sensitivity predicts intuitive disapproval of gays. Emotion, 9, 435-439. doi:10.1037/a0015960.

Iyer, R., Koleva, S., Graham, J., Ditto, P., \& Haidt, J. (2012). Understanding libertarian morality: The psychological dispositions of self-identified libertarians. PloS One, 7, e42366. doi:10.1371/journal.pone.0042366

Janoff-Bulman, R., \& Sheikh, S. (2011). Unintended consequences of moral "over-regulation". Emotion Review, 3, 325-327. doi:10.1177/1754073911402379

Jarudi, I. N. (2009). Everyday morality and the status quo: Conservative concerns about moral purity, moral evaluations of everyday objects, and moral objections to performance enhancement. (Doctoral dissertation, Yale University).

Johnson, D. J., Wortman, J., Cheung, F., Hein, M., Lucas, R. E., Donnellan, M. B., . . Narr, R. K. (2016). The effects of disgust on moral judgments: Testing moderators. Social Psychological and Personality Science, 7, 640-647. doi:10.1177/1948550616654211

Jones, A., \& Fitness, J. (2008). Moral hypervigilance: The influence of disgust sensitivity in the moral domain. Emotion, 8, 613-627. doi:10.1037/a0013435

Koleva, S., Graham, J., Haidt, J., Iyer, R., \& Ditto, P. H. (2012). Tracing the threads: How five moral concerns (especially Purity) help explain culture war attitudes. Journal of Research in Personality, 46, 184-194. doi:10.1016/j.jrp.2012.01.006 
Krosnick, J. A., Boninger, D. S., Chuang, Y. C., Berent, M. K., \& Carnot, C. G. (1993). Attitude strength: One construct or many related constructs? Journal of Personality and Social Psychology, 65, 1132-1151. doi:10.1037/0022-3514.65.6.1132

Landy, J. F., \& Goodwin, G. P. (2015). Does incidental disgust amplify moral disgust? A meta analytic review of experimental evidence. Perspectives on Psychological Science, 10, 518-536. doi:10.1177/1745691615583128

Markus, K. A., \& Borsboom, D. (2013). Frontiers of test validity theory: Measurement, causation, and meaning. New York: Routledge. doi:10.1111/jedm.12055

Matchett, G., \& Davey G. C. L. (1991). A test of a disease-avoidance model of animal phobias. Behaviour Research \& Therapy, 29, 91-94. doi:10.1016/S0005-7967(09)80011-9

Morey, R. D., \& Rouder, J. N. (2014). BayesFactor 0.9.12-2. Comprehensive R Archive Network. Retrieved from http://cran.r-project.org/web/packages/BayesFactor/index.html

Muris, P., Merckelback, H., Schmidt, H., \& Tierney, S. (1999). Disgust sensitivity, trait anxiety and anxiety disorders symptoms in normal children. Behaviour Research and Therapy, 37, 953-961. doi:10.1016/S0005-7967(99)00045-5

Navarrete, C. D., \& Fessler, D. M. T. (2006). Disease avoidance and ethnocentrism: The effects of disease fears and disgust sensitivity on intergroup attitudes. Evolution and Human Behavior, 27, 270-282. doi:10.1016/j.evolhumbehav.2005.12.001

Okimoto, T. G., \& Gromet, D. M. (2016). Differences in sensitivity to deviance partly explain ideological divides in social policy support. Journal of Personality and Social Psychology, 111, 98-117. doi:10.1037/pspp0000080 
Olatunji, B. O. (2008). Disgust, scrupulosity and conservative attitudes about sex: Evidence for a mediational model of homophobia. Journal of Research in Personality, 42, 1364-1369. doi:10.1016/j.jrp.2008.04.001

Olatunji, B. O., Williams, N. L., Tolin, D. F., Sawchuck, C. N., Abramowitz, J. S., Lohr, J. M., \& Elwood, L. (2007). The Disgust Scale: Item analysis, factor structure, and suggestions for refinement. Psychological Assessment, 19, 281-197. doi:10.1037/1040-3590.19.3.281

Rosseel, Y. (2012). Lavaan: An R package for structural equation modeling. Journal of Statistical Software, 48, 1-36. doi:10.18637/jss.v048.i02

Rozin, P., Haidt, J., \& McCauley, C. R. (2000). Disgust. In M. Lewis \& J. M. Haviland-Jones (Eds.), Handbook of emotions, $2^{\text {nd }}$ Edition (pp. 637-653). New York: Guilford Press.

Rozin, P., Haidt, J., McCauley, C. R., Dunlop, L., \& Ashmore, M. (1999). Individual differences in disgust sensitivity: Comparisons and evaluations of paper-and-pencil versus behavioral measures. Journal of Research in Personality, 33, 330-351. doi:10.1006/jrpe.1999.2251

Rozin, P., Lowery, L., Imada, S., \& Haidt, J. (1999). The CAD triad hypothesis: A mapping between three moral emotions (contempt, anger, disgust) and three moral codes (community, autonomy, divinity). Journal of Personality and Social Psychology, 76, 574 -586. doi:10.1037/ 0022-3514.76.4.574

Schein, C., \& Gray, K. (in press). The theory of dyadic morality: Reinventing moral judgments by redefining harm. Personality and Social Psychology Review. doi:10.1177/1088868317698288 
Schnall, S., Haidt, J., Clore, G. L., \& Jordan, A. H. (2008). Disgust as embodied moral judgment. Personality \& Social Psychology Bulletin, 34, 1096-1109. doi: $10.1177 / 0146167208317771$

Shweder, R. A., Much, N. C., Mahapatra, M., \& Park, L. (1997). The "Big Three" of morality (autonomy, community, divinity) and the "Big Three" explanations of suffering. In A. Brandt \& P. Rozin (Eds.), Morality and health (pp. 119-169). New York: Routledge

Smith, K. B., Oxley, D., Hibbing, M. V., Alford, J. R., \& Hibbing, J. R. (2011). Disgust sensitivity and the neurophysiology of left-right political orientations. PloS One, 6, e25552. doi:10.1371/journal.pone.0025552

Spielberger, C. D. (1999). State-Trait Anger Expression Inventory—Revised. Odessa, FL: Psychological Assessment Resources. doi:10.1002/9780470479216.corpsy0942

Tannenbaum, D., Uhlmann, E. L., \& Diermeier, D. (2011). Moral signals, public outrage, and immaterial harms. Journal of Experimental Social Psychology, 47, 1249-1254. doi:10.1016/j.jesp.2011.05.010

Terrizzi, J. A., Shook, N. J., \& Ventis, L. (2010). Disgust: A predictor of social conservatism and prejudicial attitudes toward homosexuals. Personality and Individual Differences, 49, 587-592. doi:10.1016/j.evolhumbehav.2012.10.003

Tybur, J. M., Inbar, Y., Aarøe, L., Barclay, P., Barlow, F. K., De Barra, M., ... Žezelj, I. (2016). Parasite stress and pathogen avoidance relate to distinct dimensions of political ideology across 30 nations. Proceedings of the National Academy of Sciences, 113, 12408-12413. doi:10.1073/pnas.1607398113 
Tybur, J. M., Lieberman, D. L., \& Griskevicius, V. G. (2009). Microbes, mating, and morality: Individual differences in three functional domains of disgust. Journal of Personality and Social Psychology, 29, 103-122. doi:10.1037/a0015474

Tybur, J. M., Lieberman, D., Kurzban, R., \& DeScioli, P. (2013). Disgust: Evolved function and structure. Psychological Review, 120, 65-84. doi:10.1037/a0030778

Tybur, J. M., \& De Vries, R. E. (2013). Disgust sensitivity and the HEXACO model of Personality. Personality and Individual Differences, 55, 660-665. doi:10.1016/j.paid.2013.05.008

Van Leeuwen, F., Dukes, A., Tybur, J. M., \& Park, J. H. (2017). Disgust sensitivity relates to moral foundations independent of political ideology. Evolutionary Behavioral Sciences, 11, 92-98. doi:10.1037/ebs0000075

Viechtbauer, W. (2010). Conducting meta-analyses in R with the metafor package. Journal of Statistical Software, 36, 1-48. doi:10.18637/jss.v036.i03

Visser, P. S., Bizer, G. Y., \& Krosnick, J. A. (2006). Exploring the latent structure of strength related attitude attributes. In M. Zanna (Ed.), Advances in Experimental Social Psychology, Vol. 38 (pp. 1-67). New York, NY: Academic Press.

Wang, X., Yang, L., Yang, J., Wang, P., \& Lei, L. (2017). Trait anger and cyberbullying among young adults: A moderated mediation model of moral disengagement and moral identity. Computers in Human Behavior, 73, 519-526. doi:10.1016/j.chb.2017.03.073

Wheatley, T., \& Haidt, J. (2005). Hypnotic disgust makes moral judgments more severe. Psychological Science, 16, 780-784. doi:10.1111/j.1467-9280.2005.01614.x 
Wittmann, M., Arce, E., \& Santisteban, C. (2008). How impulsiveness, trait anger, and extracurricular activities might affect aggression in school children. Personality and Individual Differences, 45, 618-623. doi:10.1016/j.paid.2008.07.001 


\section{Tables}

Table 1

Names and descriptions of moral domains in the Moral Foundations Theory.

\begin{tabular}{lll}
\hline Names & Type of Domain & Description \\
\hline Purity & Binding & Concerns contamination threats and violations of sanctity and chastity \\
Authority & Binding & Concerns disobedience and disrespect towards authorities \\
Loyalty & Binding & Concerns behaviors threatening the in-group, such as betrayal \\
Care & Individualizing & Concerns harmful acts causing suffering or distress \\
Fairness & Individualizing & Concerns (a lack of) cooperation and reciprocity \\
Liberty & Individualizing & Concerns oppression and a lack of individual freedom \\
\hline
\end{tabular}

Note: Descriptions based on Haidt (2012); Haidt \& Joseph (2007) 
Table 2

Correlation matrix of disgust sensitivity, trait anger, and all moral judgments per domain, per study.

$\begin{array}{lllllllll}M(S D) & \alpha & 2 & 3 & 4 & 5 & 6 & 7 & 8\end{array}$

Study $1(N=80)$

\begin{tabular}{|c|c|c|c|c|c|c|}
\hline 1. Disgust Sensitivity & $2.01(0.54)$ & .85 & .19 & .43 & .14 & .11 \\
\hline 2. Trait Anger & $1.86(0.45)$ & .84 & & .12 & -.05 & -.06 \\
\hline 3. Purity & $4.56(1.35)$ & $.20_{\mathrm{a}}$ & & & .23 & .25 \\
\hline 4. Authority & $4.18(0.98)$ & $.42_{\mathrm{a}}$ & & & & .20 \\
\hline 5. Care & $5.53(0.94)$ & $.13_{\mathrm{a}}$ & & & & \\
\hline 6. Fairness & $5.58(0.91)$ & $.18_{\mathrm{a}}$ & & & & \\
\hline
\end{tabular}

Study $2-$ Immorality $(N=221)$

1. Disgust Sensitivity

$1.97(0.64) \quad 88$

.19

$\begin{array}{llll}.27 & -.10 & -.06 & .01\end{array}$

2. Trait Anger

$1.76(0.41) \quad .79$

$\begin{array}{llll}-.06 & -.16 & .08 & -.04\end{array}$

3. Purity

$4.23(1.46)$

.63

$.21 \quad .25 \quad .11$

4. Authority

$4.39(1.27)$

$.44_{\mathrm{a}}$

.23

.39

5. Care

$5.24(0.94)$

.43

.36

6. Fairness

$5.92(0.81) \quad .25 \mathrm{a}$

Study 2 - Punishment $(N=221)$

\begin{tabular}{|c|c|c|c|c|c|c|}
\hline 1. Disgust Sensitivity & $1.97(0.64)$ & .88 & .19 & .38 & -.05 & .15 \\
\hline 2. Trait Anger & $1.76(0.41)$ & .79 & & .11 & -.05 & .14 \\
\hline 3. Purity & $2.55(1.30)$ & .62 & & & .31 & .37 \\
\hline 4. Authority & $3.75(1.48)$ & $.39 \mathrm{a}$ & & & & .29 \\
\hline 5. Care & $4.49(1.33)$ & .57 & & & & \\
\hline 6. Fairness & $5.31(1.37)$ & $.47_{\mathrm{a}}$ & & & & \\
\hline
\end{tabular}




$\begin{array}{lllllllll}M(S D) & \alpha & 2 & 3 & 4 & 5 & 6 & 7 & 8\end{array}$

Study $3(N=204)^{*}$

$\begin{array}{lcccccc}\text { 1. Disgust Sensitivity } & 2.05(0.54) & .84 & \mathbf{. 4 4} & .14 & \mathbf{. 3 4} & .10 \\ \text { 3. Purity } & 4.34(1.32) & .63 & & \mathbf{. 1 8} & \mathbf{. 2 7} & .10 \\ \text { 4. Authority } & 5.32(1.03) & .30 \mathrm{a} & & & \mathbf{. 3 7} & \mathbf{. 3 8} \\ \text { 5. Care } & 5.30(0.88) & .47 & & & & .27 \\ \text { 6. Fairness } & 5.75(0.81) & .27 \mathrm{a} & & & & \end{array}$

Study $4(N=148)^{*+* *}$

1. Disgust Sensitivity

$2.03(0.53)$

.84

.39

$.35 \quad .08$

3. Purity

$4.62(1.02)$

.63

. $\mathbf{3 0} \quad .11$

5. Care

$6.35(0.72)$

$.08_{\mathrm{a}}$

.23

6. Fairness

$6.02(0.89)$

$.25 \mathrm{a}$

Study $5(N=451)^{*}$

\begin{tabular}{|c|c|c|c|c|c|c|c|c|}
\hline 1. Disgust Sensitivity & $2.07(0.63)$ & .87 & .41 & .29 & .32 & .15 & .30 & .12 \\
\hline 3. Purity & $4.79(1.48)$ & .91 & & .56 & .54 & .33 & .53 & .22 \\
\hline 4. Authority & $3.27(1.22)$ & .92 & & & .69 & .38 & .81 & .52 \\
\hline 5. Care & $4.27(1.27)$ & 90 & & & & .48 & .61 & .66 \\
\hline 6. Fairness & $5.09(1.08)$ & .90 & & & & & .25 & .47 \\
\hline 7. Loyalty & $3.09(1.26)$ & .92 & & & & & & .45 \\
\hline 8. Liberty & $3.92(1.27)$ & .90 & & & & & & \\
\hline
\end{tabular}

Correlations in italics $p<.05$, correlations in bold $p<.01$

Note: Table includes means $(M)$, standard deviations $(S D)$, and reliabilities $(\alpha)$ of all subscales per study. All items were measured on a 7-point scale (1-7), except for Disgust Sensitivity, which was measured on a 5-point scale (0-4) and Trait Anger, which was measured on a 4-point scale (1-4). Reliability estimates with an a indicate correlations.

* Trait Anger was only measured in Study 1 and Study 2.

** The Authority domain was not measured in Study 4. 
Table 3

Chi-square tests comparing the free, unconstrained, model with models constraining paths to be equal (depending on which hypothesis is tested: Equal Strength Hypothesis, the Primarily Purity Hypothesis, and the Primarily Binding Hypothesis).

\begin{tabular}{|c|c|c|c|c|c|c|c|c|c|c|c|c|}
\hline & All & $\mathrm{P}-\mathrm{A}$ & P-Lo & $\mathrm{P}-\mathrm{C}$ & P-F & P-Li & A-C & A-F & A-Li & Lo-C & Lo-F & Lo-Li \\
\hline & Equal & Equal & Equal & Equal & Equal & Equal & Equal & Equal & Equal & Equal & Equal & Equal \\
\hline & $\chi^{2}(\mathrm{df})$ & $\chi^{2}$ & $\chi^{2}$ & $\chi^{2}$ & $\chi^{2}$ & $\chi^{2}$ & $\chi^{2}$ & $\chi^{2}$ & $\chi^{2}$ & $\chi^{2}$ & $\chi^{2}$ & $\chi^{2}$ \\
\hline Studies $1-4$ & & $\mathrm{df}=1$ & $\mathrm{df}=1$ & $\mathrm{df}=1$ & $\mathrm{df}=1$ & $\mathrm{df}=1$ & $\mathrm{df}=1$ & $\mathrm{df}=1$ & $\mathrm{df}=1$ & $\mathrm{df}=1$ & $\mathrm{df}=1$ & $\mathrm{df}=1$ \\
\hline Study 1 & $15.76(3)$ & 7.18 & & 8.97 & 15.38 & & 0.07 & 3.96 & & & & \\
\hline Study $2-$ Immorality & $26.25(3)$ & 20.82 & & 19.68 & 13.18 & & 0.51 & 2.63 & & & & \\
\hline Study 2 - Punishment & $28.73(3)$ & 27.78 & & 9.08 & 11.67 & & $5.59 \mathrm{a}$ & $4.98 \mathrm{a}$ & & & & \\
\hline Study 3 & 27.19 & 17.34 & & 8.53 & 24.52 & & $4.25 \mathrm{a}$ & 0.75 & & & & \\
\hline Study 4 & $9.90(2)$ & & & 2.93 & 9.76 & & & & & & & \\
\hline Study 5 & $52.18(5)$ & 16.78 & 13.29 & 10.55 & 41.96 & 32.05 & 0.90 & 11.49 & 12.72 & 0.24 & 10.85 & 12.79 \\
\hline
\end{tabular}

Chi-squares in italics $p<.05$, chi-squares in bold $p<.01$

Note: $\mathrm{df}=$ degrees of freedom, $\mathrm{P}=$ Purity, $\mathrm{A}=$ Authority, Lo = Loyalty, $\mathrm{C}=$ Care, $\mathrm{F}=$ Fairness, Li $=$ Liberty.

E.g., "P-A Equal" displays a model comparison between the free, unconstrained, model and a model in which the path between disgust sensitivity and the purity domain is constrained to be equal to the path between disgust sensitivity and the authority domain.

For ${ }_{a}$, the path coefficient of disgust sensitivity and the authority domain is significantly weaker than the path coefficient of disgust sensitivity and moral judgments of the tested moral domain (contradictory to the primarily binding hypothesis). 
Figures

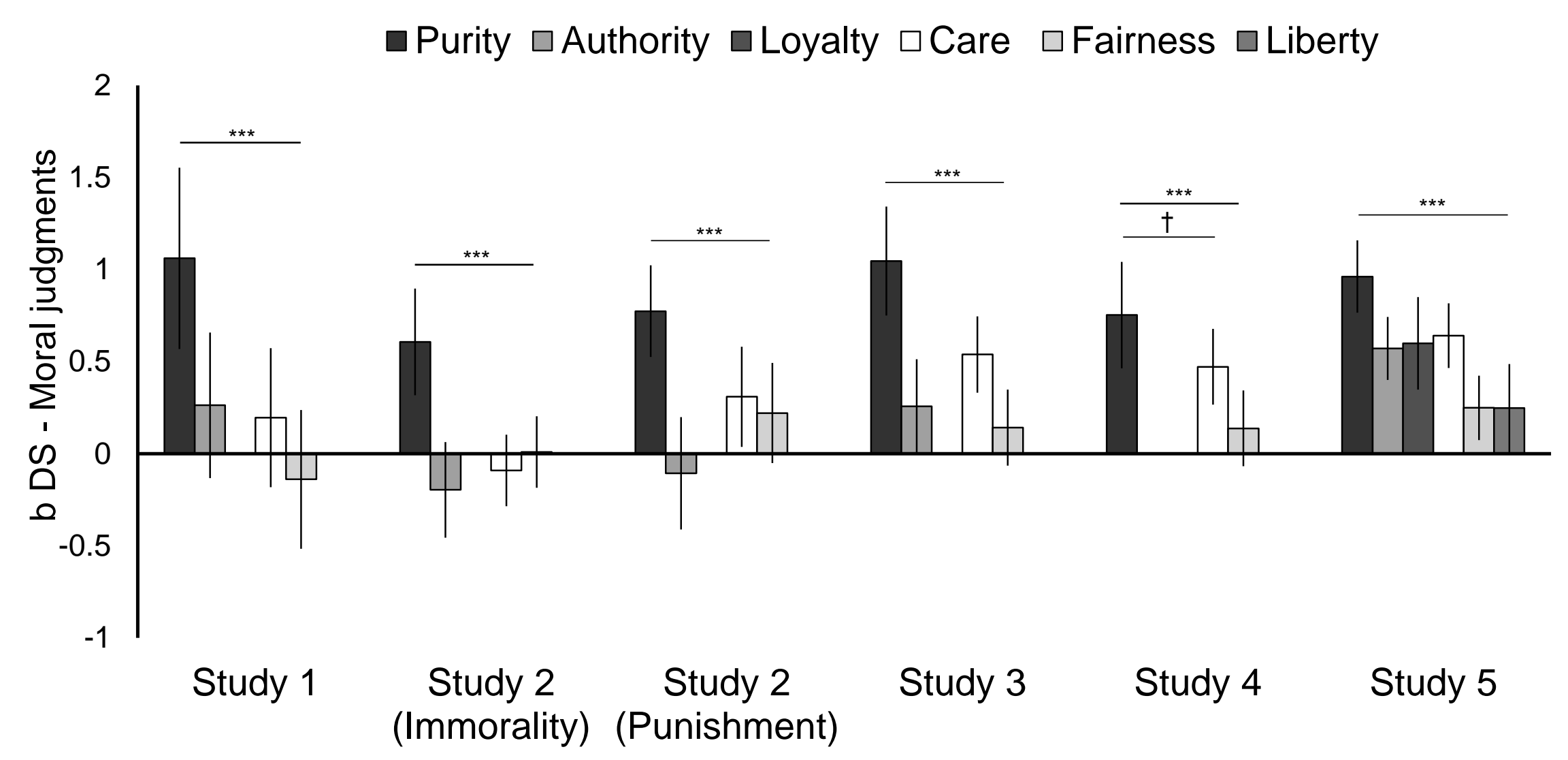

Figure 1. Unstandardized regression coefficients (b) and 95\% confidence intervals for the relation between disgust sensitivity and moral judgments for each moral domain per study, $\dagger p=.09, * * * p<.001$. 